\title{
KONTRIBUSI AGROFORESTRI HERBAL TERHADAP PENERIMAAN TUNAI MASYARAKAT LOKAL DI SEKITAR MANOKWARI UTARA (STUDI KASUS DI KAMPUNG BREMI, NYOOM I, DAN LEBAU)
}

\author{
(Contribution of Herbs Agroforestry towards Direct Income for the Local Inhabitant \\ Around North Manokwari [Study Case in Bremi, Nyoom I, and Lebau Villages])
}

\author{
MARYANCE I. IHALAUW ${ }^{1}$, ADITYA RAHMADANIARTI ${ }^{1 凶}{ }^{\circledR}$ NOVITA PANAMBE $^{1}$ \\ Jurusan Kehutanan, Fakultas Kehutanan Universitas Papua Manokwari, Papua Barat, 98314. \\ Tlp/Fax: +62986211065. \\ ${ }^{\square}$ Penulis Korespondensi: Email: aditya rahmadaniarti@yahoo.com \\ Diterima: 10 Agust 2020| Disetujui:12 Okt 2020
}

\begin{abstract}
Abstrak. Sistem agroforestri merupakan pengelolaan lahan dan system pemanfaatan yang mengkobinasikan tanaman kehutan dan pertanian. Penelitian ini bertujuan untuk menemukan komposisi pemanfaatan tanaman herbal dan tanaman hutan dengan tujuan memperoleh dan meningkatkan pendapatan ekonomi. Penelitian ini dilaksanakan di distrik Mnokwari Utara dengan focus pada tiga kampung antara lain Bremi, Nyoom I, and Lebau dengan menggunakan metode studi kasus melalaui teknik pengamatan. Hasil penelitian memperihatkan bahwa tercatat ada 6 (enam) spesies tanaman herbal yang didominasi oleh serai (Cymbopongon nardusi) dan kunyit (Curcuma longa), sedangkan tanaman non herbal tercatat sebanyak 12 (duabelas) spesies yang didominasi oleh pisang (Musa sp) dan cabe (Capsicum annum). Berdasarkan komponen penyusun agroforestry lahan kebun yang dikembangkan oleh masyarakat tergolong Agrisilviculture dengan pola tanam acakcampur (random mixture) dan trees along border pada system perladangan berpindah (shifting cultivation). Penerimaan tunai yang diperoleh masyarakat lokal pada agroforestry berkisar antara Rp. 10.597 - Rp. 36.684 dengan rata-rata Rp. 13.043 (kk/Thn), sedangkan non herbal berkisar antara Rp. 1.465 .937 Rp. 1.549.677(kk/ Thn) dengan rata-rata Rp. 1.489 .173 (kk/ Thn). Tanaman herbal memberikan kontribusi terhadap penerimaan tunai masyarakat yaitu berkisar antara $-0,71-2,37 \%$ dengan rata-rata $0,85 \%$.
\end{abstract}

Kata kunci: Agroforestri, herbal, pendapatan cash, komunitas lokal

Abstract. Agroforestry is a land management and utilization system that combines plants with food crops. This research is aiming at finding out the composition of herbaceous plants, plant structure and herbal contribution toward the community cash income. The research was conducted in sub-district of north Manokwari by focusing on Bremi, Nyoom I, and Lebau villages through study case with field observation technique. The results showed that there wehich have been dominated for the locals such as lemongrass (Cymbopongon nardusi) and tumeric (Curcuma longa), while the non-herbaceous plants that has been used around 12 species dominated by the banana (Musa sp) and chili (Capsicum annum). Based on local development pattern of agroforestry, it has been indicated as an agrisilviculture by way of randomly mixture tress along border through shifting cultivation land system. The cash income emanating from agroforestry-based pattern for herbaceous ranging between IDR 10,597,- - 36,684,- (household/year) with the average of IDR 13,043,- (household/year). Otherwise, non-herbaceous incomes were ranging between IDR 1,465,937 - 1,549,677 
(household/year) with the average of IDR 1,489,173 (household/year). The contribution of herbaceous plants to the cash income was ranged between $-0.71-2.37 \%$ with the average of $0.85 \%$.

Keywords : Agroforestry, herbaceous, cash income, local community

\section{PENDAHULUAN}

Hutan rakyat merupakan hutan yang dibangun, di kelola, dan dimanfaatkan oleh rakyat atas tanah milik atau yang dibebani hak atas tanah. Dewasa, hutan rakyat mampu memberikan kontribusi khususnya pada sektor ekonomi di Indonesia. Dalam kesulitan yang terjadi dewasa terkait berkurangnya luas kawasan hutan Indonesia, hutan rakyat seolah tumbuh mengatasi permasalahan yang terjadi. Dalam beberapa tahun belakangan ini, khususnya di pulau jawa, Hutan rakyat mulai banyak dipelajari dan didukung oleh pemerintah.

Hutan rakyat di lapangan tidak berwujud murni tetapi, dalam bentuk campuran pepohonan dengan tanaman pertanian, buahbuahan dan pangan lainnya, yang di kenal atau disebut sebagai agroforestri. Agroforestri merupakan sistem penggunaan lahan yang mengkombinasikan tanaman berkayu dengan tanaman tidak berkayu (kadang-kadang dengan hewan) yang tumbuh bersamaan atau bergiliran pada suatu lahan, untuk memperoleh berbagai produk dan jasa (service) sehingga terbentuk interaksi ekologis dan ekonomis antara komponen tanaman (Huxley, 1999).

Perkiraan potensi dan luas hutan rakyat yang berwujud agroforestri yang di himpun dari instansi kehutanan diseluruh Indonesia mencapai 39.416.557 $\mathrm{m}^{3}$ dengan luas 1.568.415,64 ha, sedangkan data potensi berdasarkan sensus pertanian yang dilakukan oleh BPS (2016) menunjukkan bahwa potensi agroforestri mencapai $39.564 .003 \mathrm{~m}^{3}$ dengan luas 1.560.229 ha,

Pengusahaan agroforestri sejauh ini hanya sebatas masyarakat pedesaan, sehingga kontribusinya hanya berdampak pada tingkat ekonomi hutan rakyat secara langsung dapat dirasakan masing- masing masyarakat lokal para pelakunya dan secara tidak langsung berpengaruh pada perekonomian desa.

Herbal merupakan salah satu jenis tanaman yang sering di temukan dalam pola agroforestri dan di hutan alam. Contoh herbal yang sering di gunakan masyarakat lokal antara lain jahe, serai, temulawak, kunyit, kumis kucing dan lain-lainnya.

Dalam hutan Indonesia menurut Fellows (1920) terdapat sekitar 30.000 jenis tanaman dan sekitar 7000 diantaranya merupakan tanaman yang berkhasiat obat. Dengan kekayaan flora tersebut maka negara kita memungkinkan untuk melakukan pengembangan industri di bidang obat - obatan. Penduduk asli (indegenous people) memiliki pengetahuan secara turun menurun dalam mengatasi permasalahan kesehatan dan juga menyakini bahwa tumbuhan yang ada dapat memberikan dampak kesehatan serta memiliki nilai ekonomis yang tinggi (Cabuy dkk. 2012).

Kontribusi yang dapat di peroleh dengan sistem agroforestri terhadap penerimaan tunai adalah masyarakat lokal mendapatkan hasil dari lahan hutan tanpa harus menunggu masa tebang karena dapat memperoleh hasil dari tanaman pertanian serta daur ulang sisa tanaman. Hal ini jelas sangat mengutungkan masyarakat lokal karena dapat memperoleh manfaat ganda dari tanaman pertanian dan kehutanan. Adapun tujuan dari penelitina ini antara lain untuk mengetahui kontribusi agroforestri herbal terhadap penerimaan tunai, mengetahui pola pertanaman agroforesti yang di terapkan oleh masyarakat lokal, serta mengetahui komposisi jenis tanaman herbal pada lahan kebun masyarakat lokal di kampung sasaran penelitian 


\section{METODE PENELITIAN}

Penelitian dilakukan pada 3 (tiga) kampung yang jumlah Kepala Keluarga (KK) terbanyak dan selain itu juga ketiga kampung tersebut terdapat tanaman Herbal di kebun.Kampung yang terpilih sebagai lokasi sasaran penelitian yaitu : Kampung Bremi, Kampung Nyoom I, dan Kampung Lebau. Waktu penelitian dilaksanakan mulai dari tanggal 8 Juni sampai dengan 5 Juli 2017.

\section{Bahan dan Alat}

Bahan yang di perlukan dalam penelitian ini adalah : tanaman herbal. Alat yang di gunakan dalam penelitian ini adalah : Daftar pertanyaan atau kuisioner, rol meter, buku lapangan (tally sheet), alat tulis menulis, kamera, GPS, haga, parang, dan talli rafia.

\section{Subjek Penelitian}

Subjek penelitian ini adalah masyarakat lokal yang melakukan tanaman herbal pada lahan agroforestri.

\section{Metode dan Teknik Penelitian}

Metode yang digunakan dalam penelitian ini adalah metode deskriptif dengan teknik observasi lapangan. Observasi lapangan di lakukan melalui pengukuran langsung terhadap objek penelitian dan wawancara langsung (wawancara terstruktur) dengan subjek penelitian.

\section{Pelaksanaan Penelitian}

\section{Pengambilan Sampel}

Penentuan responden dalam penelitian ini menggunakan teknik observasi lapangan yaitu dengan intensitas contoh sebesar $10 \%$ terhadap jumlah kepala keluarga masyarakat yang menanam tanaman herbal pada tiga kampung sasaran penelitian. Dengan demikian jumlah responden contoh kampung Bremi sebanyak 10 kepala keluarga, Kampung Nyoom I sebanyak 10 kepala keluarga dan Kampung Lebau 3 kepala kelurga dengan total responden $23 \mathrm{KK}$ (kepala keluarga). Pemilihan responden contoh menggunakan metode acak sederhana (simple random sampling) dengan kerangka pengambilan contoh adalah daftar kepala keluarga $(\mathrm{KK})$ yang menanam tanaman herbal pada lahan kebun di setiap kampung sasaran penelitian.

\section{Pengumpulan Data}

a. Data tanaman herbal, meliputi jumlah jenis, jumlah individu per jenis, luas lahan kebun, pola pertanaman serta struktur tanamannya.

b. Data nilai ekonomi tanaman herbal, meliputi jumlah tanaman herbal, frekuensi panen, jumlah sekali panen, jumlah panenan, jumlah di jual serta tempat penjualan.

c. Sumber penerimaan lain di luar penerimaan tanaman herbal di lahan kebun, meliputi jenis sumber penerimaan, dan besar penerimaan persatuan waktu.

Rincian dari data-data yang dikumpulkan termasuk satuan ukuran yang akan digunakan dirincikan dalam kuisioner dan daftar pertanyaan kunci terlampir.

\section{Variabel Pengamatan}

Variabel utama yang di amati dalam penelitian ini adalah :

1. Komponen penyusun Agroforestri

2. Frekuensi Panen / tahun

3. Penerimaan tunai masyarakat lokal/bulan

Kontribusi tanaman herbal terhadap penerimaan tunai masyarakat lokal.

Total penerimaan tunai di hitung dengan menggunakan rumus sebagai berikut (Hernanto 1988) dalam Asmi dkk. (2013) :

$$
\mathrm{Pt}=\mathrm{Ph}+\mathrm{Pnh}
$$

\section{Keterangan :}

$\mathrm{Pt}=$ total penerimaan tunai $(\mathrm{Rp} / \mathrm{Thn})$

$\mathrm{Ph}=$ Penerimaan tunai dari tanaman herbal (Rp/Thn)

Pnh = Penerimaan tunai dari non Tanaman herbal (Rp/Thn)

Sedangkan untuk menentukan nilai kontribusi tanaman herbal terhadap penerimaan tunai masyarakat digunakan 
rumus sebagai berikut :

$\mathrm{Pkh}(\%)=(\mathrm{Ph} / \mathrm{Pt}) \times 100$

Keterangan :

$\mathrm{Pkh}=$ Kontribusi tanaman herbal terhadap penerimaan tunai RT (\%)

$\mathrm{Ph}=$ Penerimaan tunai dari tanaman herbal $(\mathrm{Rp} / \mathrm{thn})$

$\mathrm{Pt}=$ Total penerimaan tunai $\mathrm{RT}(\mathrm{Rp} /$

Thn)

4. Luas lahan

5. Jumlah populasi setiap jenis

6. Penghasilan sekali panen

Sedangkan untuk variabel penunjang adalah keadaan umum lokasi penelitian

\section{Analisis Data}

Data hasil penelitian dianalisis menggunakan statistik deskriptif menggunakan selang pendugaan (Confidence interval) pada selang kepercayaan $80 \%$. Penyajian data hasil analisis menggunakan ilustrasi table dan gambar.

$\bar{X}=\frac{\sum_{i=1}^{n} \quad \mathrm{Xi}}{n}$

$s^{2}=\frac{\mathrm{n}_{\sum_{\mathrm{i}=1}^{n}}^{n} \mathrm{xi}^{\mathrm{n}}-\left(\sum_{\mathrm{i}=1}^{\mathrm{n}} \mathrm{Xi}^{2}\right)^{\mathrm{m}}}{\mathrm{n}(\mathrm{n}-1)}$ Maka S $=\sqrt{S^{2}}$

$S^{2}=\bar{X} \frac{\mathrm{s}^{\mathrm{m}}}{n}\left(\frac{\mathrm{N}-\mathrm{n}}{\mathrm{n}}\right)$, Untuk populasi terbatas

$S^{2}=\frac{\mathrm{s}^{3}}{n}\left(\frac{\mathrm{N}-\mathrm{n}}{\mathrm{n}}\right)$, Untuk populasi tak terbatas

Sehingga $S_{\bar{X}}=\sqrt{S_{\bar{X}}^{2}}$

$\hat{x}=\mathrm{N} \cdot \bar{X}$

$\mathrm{C}=\frac{s}{\bar{x}}$

Keterangan :

$\bar{X}$ : rata - rata nilai $\mathrm{X}$ persatuan contoh (sebagai dugaan dari rata - rata populasi)

$\mathrm{n}$ : Jumlah satuan contoh yang dipilih

$\mathrm{Xi}$ : nilai besaran X (desinty, volume, dan lain lain) yang diukur dalam satuan contoh

$\mathrm{N}$ : jumlah satuan contoh dalam populasi

$\mathrm{S}$ : standar deviasi dari contoh

$S_{\bar{X}}:$ standar eror dari rata - rata $(\mathrm{SEM})$ $\hat{x}$ : dugaan nilai total

$\mathrm{C}$ : koefisien variasi

Selang pendugaan interval dengan ukuran sampel lebih besar dari $30 \quad(n \quad>30)$ menggunakan rumus berikut (Hasan 2001) :

$$
\bar{X}-Z_{a / 2} \cdot \frac{\sigma}{\sqrt{n}}<\mu<\bar{X}+Z_{a / 2} \cdot \frac{\sigma}{\sqrt{n}}
$$

Keterangan :

$\bar{X}-\mathrm{Za} / 2 \sigma \quad$ : batas bawah pendugaan interval

$\bar{X}+\mathrm{Za} / 2 \sigma \quad:$ batas atas pendugaan interval

$\mathrm{Za} / 2 \quad$ : koefisien yang sesuai dengan interval keyakinan yang digunakan dalam pendugaan interval dan nilainya diberikan dalam tabel luas kurva normal.

$\sigma \quad:$ simpangan baku

$\mu \quad$ : rata- rata populasi

\section{HASIL DAN PEMBAHASAN}

\section{Komposisi Jenis Tanaman Herbal dan Jenis Tanaman Non Herbal}

Berdasarkan hasil penelitian yang dilakukan di Distrik Manokwari Utara pada tiga kampung yaitu Bremi, Nyoom I dan Lebau terdapat jumlah komposisi jenis tanaman herbal sebanyak 6 (enam) jenis dan tanaman bukan herbal sebanyak 12 (dua belas) jenis. Dari 6 (enam) spesies pada ketiga kampung tersebut lebih didominasi oleh jenis serai (Cymbopongon nardus) dan kunyit (Curcuma longa). Komposisi jenis tanaman gerbal disajikan pada Tabel 1. Sedangkan tanaman non herbal terdiri dari 13 (tiga belas) spesies, yang didominasi oleh pisang (Musa paradisiaca) dan cabe (Capsicum annum). Komposisi jenis tanaman non herbal pada kampung pengamatan seperti disajikan pada Tabel 2. 
Tabel 1. Komposisi jenis tanaman herbal di tiga kampung distrik Manokwari Utara

\begin{tabular}{lclc}
\hline Kampung & Jenis Tanaman & Nama Latin & Jumlah tanaman \\
\hline \multirow{3}{*}{ Bremi } & Kunyit & Curcuma longa & 31 \\
& Jahe & Zingiber officinale & 21 \\
& Serai & Cymbopongon nardus & 45 \\
\multirow{3}{*}{ Nyoom I } & Lengkuas & Alpinia galanga & 8 \\
& Kunyit & Curcuma longa & 38 \\
& Lengkuas & Alpinia galanga & 44 \\
& Serai & Cymbopongon nardus & 21 \\
\hline \multirow{4}{*}{ Lebau } & Kunyit & Curcuma longa & 22 \\
& Lengkuas & Alpinia galanga & 19 \\
& Kemangi & Ocimum z citriodorum & 13 \\
& Serai & Cymbopongon nardus & 27 \\
& Jahe & Zingiber officinale & 4 \\
\hline
\end{tabular}

Tabel 2. Jenis tanaman bukan herbal di tiga kampung distrik Manokwari Utara

\begin{tabular}{lclc}
\hline Kampung & Jenis Tanaman Non & Nama Latin & $\begin{array}{l}\text { Jumlah } \\
\text { Tanaman }\end{array}$ \\
\hline Bremi & Kacang panjang & Vigna unguiculata. Ssp & 33 \\
& Cabe & Capsicum annum & 289 \\
& Pisang & Musa paradisiaca & 319 \\
Betatas & Ipomoea batatas & 64 \\
Sayur gedi & Abelmoschus manihot & 26 \\
& Pinang & Areca catechu & 25 \\
& Sayur katuk & Sauropus androgynus & 10 \\
\hline Nyoom I & Cabe & Capsicum annum & 50 \\
& Betatas & Ipomoea batatas & 32 \\
& Keladi & Caladium & 13 \\
& Sawi putih & Brassica rapa subsp & 70 \\
Pisang & Musa paradisiaca & 55 \\
\hline Lebau & Cabe & Capsicum annum & 100 \\
& Pepaya & Carica papaya & 12 \\
& Pisang & Musa paradisiaca & 382 \\
& Pinang & Areca catechu & 14 \\
Kasbi & Manihot esculenta & 125 \\
& Jagung & Zea mays & 60 \\
Keladi & Caladium & 65 \\
& Betatas & Ipomoea batatas & 48 \\
Mangga & Mangifera indica & 2 \\
\hline
\end{tabular}

Pola Pertanaman Masyarakat Lokal

Dari hasil pengamatan, berdasarkan komponen penyusun agroforestri kebun yang dikembangkan oleh masyarakat lokal tergolong agrisilvikultur (kombinasi tanaman berkayu dan tanaman pertanian) dengan bentuk pola pertanamannya adalah random mixture (acak 
campur) serta trees along border, dimana lahan kebun masyarakat lokal merupakan hasil dari pembukaan lahan hutan (perladangan berpindah/shifting cultivation).
Pola pertanaman yang tidak teratur ini menyebabkan struktur tanamannya menjadi sangat kompleks. Pola pertanaman masyarakat dapat dilihat pada Gambar 1.
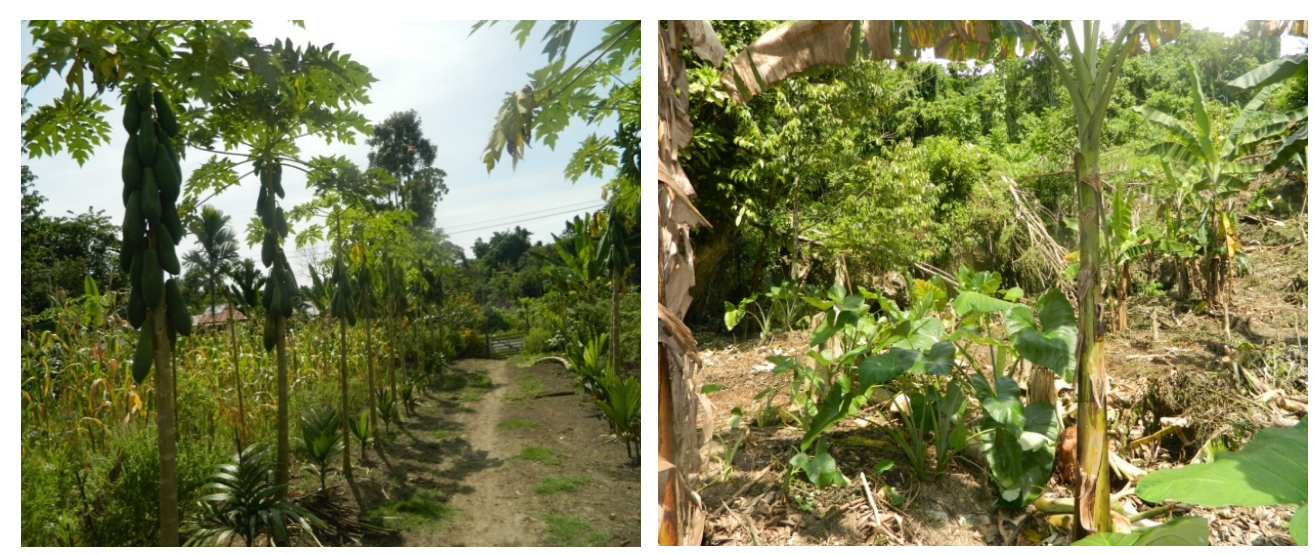

Gambar 1. Contoh bentuk pola pertanaman kebun masyarakat lokal di kampung Bremi, Nyoom I, dan Lebau.

Pada gambar 1 nampak bahwa masyarakat lokal menanam jenis tanaman secara acak/random pada lahan kebun mereka. Jenisjenis tanaman non herbal yang ditanam seperti kacang panjang, cabe, pisang, betatas, sayur gedi, sayur katuk, keladi, kasbi, sawi putih, pepaya, pinang, dan jagung.

\section{Penerimaan Tunai Masyarakat Lokal}

Penerimaan tunai merupakan hasil yang diperoleh petani dari usaha tani lahan kebun baik berupa komoditi yang dijual maupun komoditi yang dikonsumsi (Marhalim 2015).
Pada penelitian ini, penerimaan tunai yang diperoleh masyarakat lokal pada ketiga kampung tersebut dari sistem agroforestri kebun merupakan penerimaan sampingan dari pekerjaan utama mereka. Hasil dari pemanfaatan lahan kebun sebagian besar dimanfaatkan masyarakat lokal untuk memenuhi kebutuhan konsumsi keluarga, namun ada juga yang sebagian hasil panennya dikonsumsi dan lebihnya dijual di pasar. Hasil penerimaan tunai masyarakat lokal disajikan pada Tabel 3.

Tabel 3. Penerimaan tunai masyarakat lokal dan kontribusi tanaman herbal di kampung Bremi, Nyoom I, dan Lebau, distrik Manokwari Utara

\begin{tabular}{lcccc}
\hline \multirow{2}{*}{ Variabel } & \multicolumn{4}{c}{ Nilai } \\
\cline { 2 - 5 } & Satuan & Minimum & Rataan & Maksimum \\
\hline Total penerimaan & $\mathrm{Rp} / \mathrm{KK} / \mathrm{Thn}$ & 1.502 .061 & 1.525 .869 & 1.549 .677 \\
Penerimaan Tanaman Herbal & $\mathrm{Rp} / \mathrm{KK} / \mathrm{Thn}$ & $(10.597)$ & 13.043 & 36.684 \\
Penerimaan Tanaman Non Herbal & $\mathrm{Rp} / \mathrm{KK} / \mathrm{Thn}$ & 1.465 .937 & 1.489 .173 & 1.549 .677 \\
Kontribusi Tanaman Herbal & $\%$ & $-0,71$ & 0,85 & 2,37 \\
\hline
\end{tabular}

Tabel 3 menunjukkan bahwa penerimaan tunai dari tanaman herbal berkisar antara $\mathrm{Rp}$. (10.597) - Rp. 36.684 (KK/Thn) dengan ratarata sebesar Rp. 13.043 (KK/Thn), sedangkan non herbal berkisar antara Rp. $1.465 .937-\mathrm{Rp}$. 1.549.677 (KK/Thn) dengan rata-rata sebesar Rp. 1.489.173 (KK/Thn). Bila dilihat dari ratarata total penerimaan tunai masyarakat lokal, 
tanaman herbal ternyata memberikan kontribusi yang relatif sangat kecil terhadap penerimaan tunai masyarakat yaitu berkisar antara $-0,71-$ $2,37 \%$ dengan rata-rata kontribusi sebesar $0,85 \%$.

Rendahnya nilai kontribusi tanaman herbal terhadap penerimaan tunai masyarakat lokal menunjukkan bahwa tanaman tersebut kurang memberikan kontribusi terhadap penerimaan tunai keluarga bila dibandingkan dengan jenis tanaman lain, seperti sayur-sayuran maupun tanaman MPTs. Hal ini disebabkan karena tanaman herbal lebih banyak digunakan untuk kebutuhan masyarakat itu sendiri sebagai bumbu dapur ataupun obat-obatan. Rampalino (2017) menyatakan bahwa tanaman MPTs memberikan kontribusi terhadap penerimaan tunai masyarakat lokal di Distrik Pantai Utara Manokwari sebesar 46,1384-47,1449\%.

Terbatasnya luasan dan masih ditemukan areal kosong jumlah komponen tanaman penyusun lahan kebun turut mempengaruhi tingkat penerimaan tunai keluarga. sehingga perlu dilakukan diversifikasi tanaman yang lebih beragam serta memanfaatkan areal kosong pada lahan kebun masyarakat.

Pola diversifikasi jenis komoditas dan intensifikasi pertanaman pada lahan kebun masyarakat lokal dapat dilakukan dengan mengkombinasikan antara tanaman semusim (pertanian) sebagai strategi penyediaan pangan rumah tangga dengan tanaman herbal berbasis obat-obatan, misalnya kunyit, serai, jahe, kencur dan sebagainya, serta tanaman hortikultura (tanaman MPTs) lainnya sebagai strategi untuk menambah penerimaan tunai keluarga. Dengan adanya pemanfaatan areal kosong dan diversifikasi jenis tanaman penyusun kebun maka produktivitas lahan akan meningkat dan pada saat panen, penerimaan tunai masyarakat lokal dapat ditingkatkan.

\section{KESIMPULAN}

Terdapat 6 (enam) spesies tanaman herbal yang ditemukan pada lahan kebun di kampung Bremi, Nyoom I, dan Lebau Distrik Manokwari Utara, yaitu kunyit (Curcuma longa), serai (Cymbopongon nardus), jahe (Zingiber officinale), lengkuas (Alpinia galanga), kencur (Kaempferia galanga L) dan kumangi (Ocimum $z$ citriodorum). Yang di dominansi oleh Serai dan Kunyit. Berdasarkan komponen penyusunnya, pola agroforestri yang dikembangkan oleh masyarakat adalah Agrisilvikultur, dengan bentuk pola pertanamannya adalah random mixture (acak campur), dan trees along border. Tanaman herbal memberikan kontribusi terhadap total penerimaan tunai masyarakat lokal sebesar berkisar antara $-0,71-2,37 \%$.

\section{DAFTAR PUSTAKA}

Asmi MT, Qurniati R dan Haryono D. 2013. Komposisi tanaman agroforestri dan kontribusinya terhadap pendapatan rumah tangga di desa Pesawaran Indah kabupaten Pesawaran Lampung. Jurnal Sylva Lestari, 1 (2): 55- 64.

BPS. 2016 Distrik Manokwari Utara dalam angka 2016, Manokwari Utara Subdistrict Figures. Badan pusat Statistik Kabupaten Manokwari. Di unduh pada :http/. Manokwari kab.bps.go.id (08 Oktober 2016).

Cabuy RL, Marwa J, Manusawai J and Rahawarin YY. 2012. Non-woody plant species of Papuan island forest, a sustainable source of food for the local communities. Indian Journal of Traditional Knowledge, 11 (4): 586-592.

Fellows L. 1992. The Lancet, 339, 130. Katno dan Pramono S. 2010.Tingkat manfaat dan keamanan tumbuhan obat dan obat tradisional. (Online). Jurnal tersedia di:http://cintaialam.tripod.co. Tersedia 
di:http://cintaialam.tripod.co sutarjo, R, M.1999. Pengelolaan Tanaman. Semarang Huxley P. 1999. Tropical agroforestry. Blackwell Science Ltd, UK, ISBN $0-632-$ Masyarakat dalam proyek IHMB [skripsi].

Marhalim,. 2015. Kontribusi nilai ekonomis jahan pekarangan terhadap ekonomi rumah tangga petani di desa Rambah Samo kecamatan Rambah Samo kabupaten Rokan Hulu. Artikel Ilmiah pada Fakultas Pertanian Universitas Pasir Pengaraian. http://download.garuda.ristekdikti.go.id/artic le.php?article $=399740 \& \mathrm{val}=8750 \&$ title $=\mathrm{KO}$ NTRIBUSI $\% 20$ NILAI $\% 20$ EKONOMIS $\% 2$
OLAHAN\%20PEKARANGAN\%20TERHA DAP\%20EKONOMI\%20RUMAH\%20TAN GGA\%20PETANI\%20DI\%20DESA\%20R AMBAH $\% 20$ SAMO $\% 20$ KECAMATAN $\% 2$ ORAMBAH $\% 20$ SAMO $\% 20$ KABUPATEN \%20ROKAN\%20HULU.

Rampalino D. 2017. Kontribusi tanaman MPTS pada sistem agroforestri pekarangan terhadap penerimaan tunai masyarakat lokal di kampung Bremi, kampung Menyunfoka dan kampung Lebau Distrik Manokwari Utara. Skripsi Sarjana Kehutanan Universitas Papua Manokwari. (Tidak diterbitkan). 